\title{
Influence of Fiber Coating and Polymer Modification on Mechanical and Thermal Properties of Bast/Basalt Reinforced Polypropylene Hybrid Composites
}

\author{
Anjum Saleem ${ }^{1,2, *}$, Luisa Medina ${ }^{1, *}$ and Mikael Skrifvars ${ }^{2}$ (D) \\ 1 Angewandte Logistik- und Polymerwissenschaften, University of Applied Sciences, \\ 67659 Kaiserslautern, Germany \\ 2 Swedish Centre for Resource Recovery, Faculty of Textiles, Engineering and Business, University of Borås, \\ 50332 Borås, Sweden; Mikael.Skrifvars@hb.se \\ * Correspondence: anjum.saleem@hs-kl.de (A.S.); Luisa.Medina@hs-kl.de (L.M.)
}

Received: 20 July 2020; Accepted: 13 August 2020; Published: 18 August 2020

\begin{abstract}
Natural fibers, such as kenaf, hemp, and flax, also known as bast fibers, offer several benefits such as low density, carbon dioxide neutrality, and less dependence on petroleum sources. Their function as reinforcement in polymer composites offers a great potential to replace a segment of the glass fiber-reinforced polymer composites, especially in automotive components. Despite their promising benefits, they cannot meet the structural and durability demands of automobile parts because of their poor mechanical properties compared to glass fibers. The focus of this research work was the improvement of the mechanical property profile of the bast fiber reinforced polypropylene composites by hybridization with natural high-performance basalt fibers and the influence of basalt fibers coating and polymer modification at the mechanical and thermal properties of the composites. The specific tensile strength of the composite with polymer tailored coating was $39 \%$ and the flexural strength was $44 \%$ higher than the composite with epoxy-based basalt fibers. The mechanical performance was even better when the bast/basalt hybridization was done in maleic anhydride modified polymer. This led to the conclusion that basalt fibers sizing and polymer modification are the deciding factors in defining the optimal mechanical performance of the composites by influencing the fiber-matrix interaction. The composites were analyzed for their mechanical, thermal, and morphological properties. The comparison of bast/basalt hybrid composite with bast/glass fibers hybrid composite showed a $32 \%$ higher specific flexural and tensile strength of the basalt hybrid composite, supporting the concept of basalt fibers as a natural alternative of the glass fibers.
\end{abstract}

Keywords: natural fibers; polypropylene; basalt; hybridization; mechanical; thermal; carding

\section{Introduction}

The growing interest in environmental protection, unsustainable petroleum consumption, and the European Union's strict regulations regarding the ecological impact of cars (from manufacturing and use to disposal at end-of-life) has enhanced the need for research and development of the innovative and sustainable materials [1]. Considering this, natural fiber reinforced polymer composites (NFRPC) have been adopted by the European automotive industry in the past decades. They are renewable and their lower density compared to glass fibers gives them advantages regarding weight reduction of automotive components [2-4]. From a structural viewpoint, the properties critical for the applications of composites in automobiles are the durability, strength, and energy absorption [5]. So far, the most successful reinforcement fibers for structural applications of polymer composites in the automotive industry are glass fibers $[6,7]$ since they have proven to meet the demands in automobiles because of 
their excellent strength, durability, thermal stability, and resistance to impact, friction, and wear [8,9]. Despite good mechanical and chemical properties, glass fibers exhibit certain shortcomings. They are not from renewable resources, which is a trend when moving into a circular economy. In comparison to the natural fibers $\left(1.45 \mathrm{~g} / \mathrm{cm}^{3}\right)$, the density of glass fibers $\left(2.5 \mathrm{~g} / \mathrm{cm}^{3}\right)$ is quite high that adds weight to the automotive part. Furthermore, the production of glass fibers consumes much higher energy (54.8 MJ/kg) compared to natural fibers (9.7 MJ/kg) [6].

Despite the benefits offered by NFRPC [10-14], their applications in structural components are restricted. This is due to the naturally occurring irregularities and low mechanical property profile of natural fibers, so that they cannot compete with the glass fiber reinforced polymer composites [15]. However, they would be an excellent material of choice, if the mechanical properties of NFRPC could be improved. They offer not just ecological, but also technical and economic benefits with a great potential to replace glass fibers, at least partially if not fully, in the structural applications.

Bast fibers such as kenaf, flax and hemp fiber reinforced polypropylene (PP) composites are very popular NFRPC in the nonstructural components for automotive applications because of their low density, easy processability, and capability to be recycled by energy recovery [15]. Several attempts have been reported to improve the mechanical properties of NFRPC by hybridization of natural fibers with glass, or carbon fibers [16-21]. However, the downside of this hybridization is the reduction of the amount of natural fibers, i.e., renewable content of the composites. This led to the idea of using high-performance basalt fibers in hybridization with bast fibers instead of synthetic fibers. Compared to glass fibers, they have better mechanical performance, good chemical resistance and no health hazards which makes them an excellent natural substitute of glass fibers [22-26]. Furthermore, basalt fibers have an edge of being renewable and therefore their addition to the composites would not decrease the renewable content of the composites.

Recent research by Saleem et al. [27] has demonstrated the successful production of hybrid bast/basalt polymer composites by established processing techniques like carding and compression molding, with significantly improved mechanical performance. It was spotted that the basalt fibers used in the previous study had a surface coating unsuitable for the PP matrix that led to the conclusion that the fiber-matrix interaction and accordingly the overall part performance could be further improved by using the basalt fibers with an appropriate PP-coating. Sizing or coating of basalt fibers involves the application of a thin coating to the fiber surface, which forms a chemical bond between the polymer and the fibers [26,28-30]. The fiber coating is an integral part of the manufacturing process and requires no further processing steps, making it a relatively convenient process. Another method of improving the fiber-matrix interaction is the bulk modification of the polyolefins with additives such as polypropylene grafted maleic anhydride (PP-g-MA) [31-34]. The adhesion between the plant fibers and matrix improves because the unsaturated carbon-carbon bonds of maleic anhydride can form connections with the polymer chains, whereas the anhydride groups are free to react with the hydroxyl groups at the cellulosic natural fibers. The grafting has been shown to improve the mechanical properties of plant fiber-reinforced polymer composites. It is also worth mentioning that the modification of the polymer is quite an expensive and complicated procedure since it requires additional processing steps and higher material costs. Therefore, it is not usually a preferred method in the industry due to a lack of economic efficiency [12,30,35].

The aim of present research work is the study of the effect of the surface coating of basalt fibers on the mechanical and thermal performance of bast/basalt polypropylene hybrid composites. In serial production, it is often preferred to use a mixture of natural fibers to avoid their shortfall or variabilities in the properties. Therefore, in this work, a mixture of kenaf and flax was used as bast fibers [2]. A part of the study is also dedicated to compare the influence of maleic anhydride modified PP (PP-g-MA) on the flexural and impact energy absorption properties of hybrid composites. The hybridization of basalt and bast fibers in thermoplastic polymers is inventive, therefore there is an evident lack of comparable data in the literature [27]. Therefore, a similar hybridization of bast and glass fibers in polypropylene 
was done and these composites were used as a reference to consider the producibility of bast/basalt hybrid composites.

The composites were analyzed for their mechanical performance by tensile, flexural, and impact energy absorption analysis. The morphology of the composites was investigated by scanning electron microscopy. The properties of thermoplastics composites are temperature dependent and therefore the analysis of their thermal properties is quite relevant in the industry [36]. According to literature, basalt fibers along with excellent mechanical performance have also very good thermal properties $[23,26,37,38]$. This denotes that their addition to the composites would also increase the thermal performance of the composites. Considering this, the hybrid bast/basalt composites were analyzed for their heat deflection temperature (HDT) and their thermal conductivity, as well. The analysis of the heat deflection temperature is important for the application of thermoplastic materials in the industry since it helps to determine the capacity of the material to withstand the temperature [39]. The importance of the thermal conductivity in polymer composites is associated with their use in heat dissipation applications.

\section{Materials and Methods}

\subsection{Material}

Unmodified polypropylene (PP) and with 2\% maleic anhydride modified polypropylene (PP-g-MA) melting polypropylene fibers were used as matrix. PP fibers with a linear density of $6.7 \mathrm{dtex}$ and a length of about $70 \mathrm{~mm}$ were provided by Beaulieu International Group, Belgium.

As bast fibers were selected kenaf (KE) and flax (FL), having a cut length of about $110 \mathrm{~mm}$. They were supplied by J. Dittrich \& Söhne Vliesstoffwerk GmbH, Ramstein, Germany. Basalt fibers with an epoxy compatible coating (DBA) were developed and provided by Deutsche Basalt Faser $\mathrm{GmbH}$ (Sangerhausen, Germany). Whereas, the basalt fibers with a PP compatible coating (BA) were developed and provided by Mafic Black Basalt Ltd. Ireland. Glass fibers (GF) were used to prepare hybrid composites with PP for comparison purposes. The cut length of basalt and glass fibers was approximately $90-100 \mathrm{~mm}$.

The applied fibers were tested for their linear density by vibration method according to DIN EN ISO 1973 [40] and the tensile properties according to DIN EN ISO 5079 [41] using a Favigraph from Textechno Herbert Stein GmbH \& Co. KG (Monchengladbach, Germany). The tests were conducted at a clamping length of $20 \mathrm{~mm}$ and $20 \mathrm{~mm} / \mathrm{min}$ test speed. The pre-load weight needed to stretch the fibers according to the linear density was $1000 \mathrm{mg}$ for PP and basalt fibers, $330 \mathrm{mg}$ for GF, and 10,000 $\mathrm{mg}$ for bast fibers. The results of the fiber analysis are summarized in Table 1. The applied reinforcement fibers are shown in Figure 1.

Table 1. Mechanical analysis of various fibers by Favigraph Texttechno.

\begin{tabular}{cccccccc}
\hline \multirow{2}{*}{ Properties } & \multicolumn{7}{c}{ Fiber Analysis } \\
\cline { 2 - 8 } & BA & DBA & KE & FL & PP & PP-g-MA & GF \\
\hline Elongation (Fmax) (\%) & $4 \pm 1$ & $4 \pm 1$ & $2 \pm 0.5$ & $2 \pm 0.5$ & $161 \pm 37$ & $161 \pm 37$ & $3 \pm 1$ \\
Breaking force (cN) & $53 \pm 16$ & $43 \pm 11$ & $437 \pm 275$ & $269 \pm 112$ & $21 \pm 2$ & $21 \pm 2$ & $29 \pm 10$ \\
Tenacity (cN/dtex) & $8 \pm 1$ & $8 \pm 1$ & $4 \pm 2$ & $4 \pm 1$ & $3 \pm 0.4$ & $3 \pm 0.4$ & $6 \pm 1$ \\
Linear Density (dtex) & $6.7 \pm 2$ & $6.1 \pm 1$ & $121 \pm 42$ & $81 \pm 38$ & $6.7 \pm 1$ & $6.7 \pm 1$ & $4.0 \pm 1$ \\
\hline
\end{tabular}

BA: basalt fibers with a PP compatible coating; DBA: Basalt fibers with an epoxy compatible coating; KE: Bast fibers-Kenaf; FL: Bast fibers-Flax; PP: Polypropylene; PP-g-MA: PP modified with $2 \%$ maleic anhydride; GF: Glass fibers. 


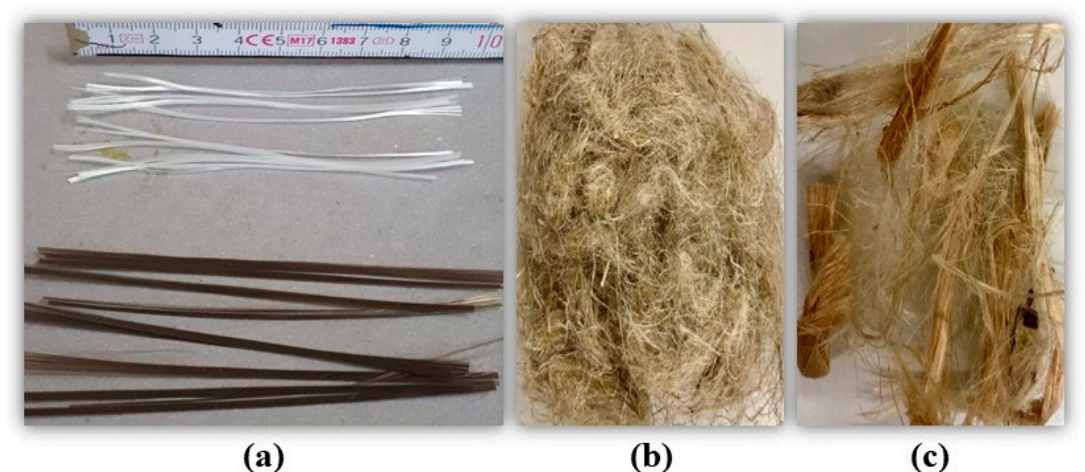

Figure 1. Applied reinforcement fibers: (a) Glass (white) and Basalt (black) fibers; (b) Flax fibers; (c) Kenaf fibers.

For each material, at least thirty fibers were analyzed, and the average values of the analysis are given in Table 1. Bast fibers are coarse fibers in the form of irregular bundles and consist of variable number of elementary fibers [12], which explains their high linear density (81 dtex and $121 \mathrm{dtex}$ ) and high breaking force $(269 \mathrm{cN}$ and $437 \mathrm{cN}$ ). The basalt, PP, and GF are fine fibers and consist of single filaments. BA and DBA fibers are similar in all aspects except that DBA fibers have less breaking force compared to the BA fibers ( $43 \mathrm{cN}$ vs. $53 \mathrm{cN}$ ). Compared to the glass fibers, the mechanical property profile of basalt fibers is clearly better than the GF regarding all the tested properties. The fiber analysis is in agreement with the literature [42] and manufacturer's specifications.

\subsection{Composites Production Method}

The first step of composite production was the carding of the fibers and the production of fiber mass of a specified area weight. The fiber mass was further needled to fiber mats which were finally compression molded to produce the test specimens for the analysis. The following section provides a detailed explanation of each step.

\subsubsection{Fiber Mat Manufacturing by Carding}

The fibers in defined compositions were passed through a complex system of roller cards with interlinked saw tooth wires. The carding opens and blends the fibers into a thin fiber web free from contaminations such as shives, soil, dirt, or short fibers. The thin fiber web coming out of the carder has evenly distributed and oriented fibers. The thin fiber web coming out of the carding machine was collected over a wooden roller rotating constantly in the clockwise direction. The thin fiber web was wound up the roller until a desired area weight was achieved. This stack of thin layers over the roller was called a fiber mass. The fibers in the fiber mass were predominantly oriented in the production direction since the roller rotates only in one direction. The fiber mass of specific area weight was removed from the roller and was sent further to the needling. Needling serves to make the fiber mass compact and optimize the adhesion between single layers and among the fibers (Figure 2). The fiber mass was needled again in the production direction, as well. The needled fiber mass was called a fiber mat which was compact enough to be easily handled in the further processing by compression molding. The fiber mats produced in this work had an area weight of approximately $1550 \pm 150 \mathrm{~g} / \mathrm{m}^{2}$. 


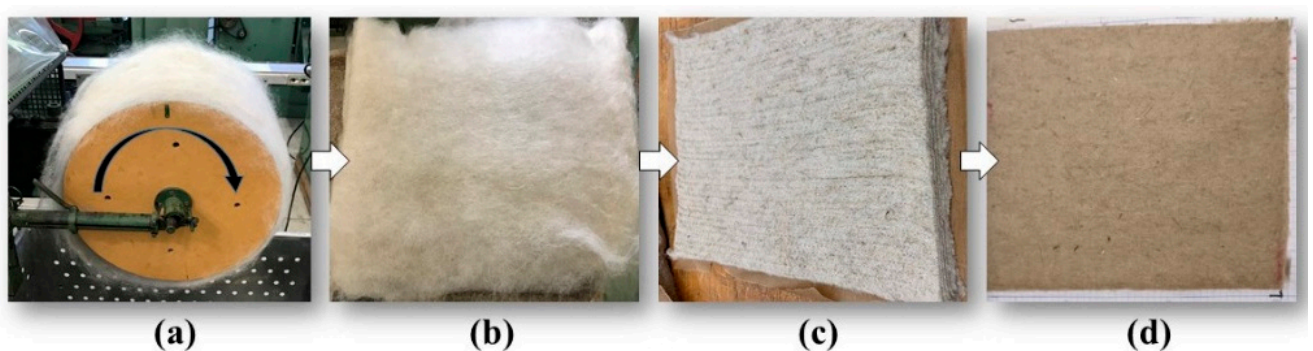

Figure 2. Composites production from carding to compression molding: (a) collection of fiber web over a rotating roller; (b) Fiber mass of a specific area weight; (c) Needled fiber mass (Fiber mat); (d) Fiber mat after compression molding, fibers are predominantly oriented in the production direction indicated by arrows.

The principal challenge in the carding process was that the various sorts of fibers such as flexible and thin PP fibers, coarse and hard bast fibers, brittle, fine GF, and basalt fibers could be homogeneously mixed in the fiber mats. Therefore, the carding process was intensely optimized to ensure a homogeneous mixture of various fibers. The homogeneity of the fiber mats was confirmed later by the morphological analysis of the composites. Table 2 highlights the compositions in weight percent (wt.\%) prepared by carding for further compression molding and analysis.

Table 2. Fiber mat compositions prepared by carding.

\begin{tabular}{ccc}
\hline Nonwovens & Abbreviation & Composition (wt.\%) \\
\hline PP reference composition & PP/KEFL & $50 \%$ PP + 50\% Bast fibers (25\% kenaf + 25\% flax) \\
& PP/5BA/KEFL & $50 \%$ PP + 5\% BA + 45\% kenaf and flax \\
& PP/10BA/KEFL & $50 \%$ PP + 10\% BA + 40\% kenaf and flax \\
PP composites with BA (PP-size) & PP/15BA/KEFL & $50 \%$ PP + 15\% BA + 35\% kenaf and flax \\
& PP/20BA/KEFL & $50 \%$ PP + 20\% BA + 30\% kenaf and flax \\
& PP/25BA/KEFL & $50 \%$ PP + 25\% BA + 25\% kenaf and flax \\
PP composition with basalt fibers & PP/40BA/KEFL & $50 \%$ PP + 40\% BA + 5\% kenaf and flax \\
(Epoxy-size) & PP/25DBA/KEFL & $50 \%$ PP + 25 \% DBA + 25\% kenaf and flax \\
PP compositions with glass fibers & PP/5GF/KEFL & $50 \%$ PP + 5\% GF + 45\% kenaf and flax \\
(PP-size) & PP/15GF/KEFL & $50 \%$ PP + 15\% GF + 35\% kenaf and flax \\
Compositions of modified PP & PP/25GF/KEFL & $50 \%$ PP + 25\% GF + 25\% kenaf and flax \\
(PP-g-MA) & PP-g-MA/KEFL & $50 \%$ PPM + 50\% Bast fibers (25\% kenaf + 25\% flax) \\
& PP-g-MA/25BA/KEFL & $50 \%$ PPM + 25\% BA + 25\% kenaf and flax \\
\hline
\end{tabular}

\subsubsection{Compression Molding}

The reference and hybrid needled fiber mats were compression molded to flat laminates for the mechanical and thermal characterization. The fiber mats of $190 \times 200 \mathrm{~mm}$ dimensions were cut from the bigger mats in the production direction and were compression molded at $200{ }^{\circ} \mathrm{C}$ (needed for melting the PP-fibers that act as a polymer matrix in the composite) using a Collin thermal press in a three-phase pressure cycle. The samples were pressed at 8 bar for $60 \mathrm{~s}$ and afterwards at 50 bar for $180 \mathrm{~s}$ to achieve a homogeneous and effective impregnation of the fibers with the PP melt. The samples were cooled down to $60^{\circ} \mathrm{C}$ under 50 bar pressure before they were taken out of the press-molding machine. The test specimens for mechanical and thermal analyses were cut from the flat laminates in the production direction.

\subsection{Characterization Methods}

The test specimens were characterized by mechanical and thermal analysis by following characterization methods:

Flexural properties were carried out using universal testing machine Zwick Roell (Ulm, Germany) according to DIN EN ISO 178 [43] at ambient temperature. The support span was fixed at $39 \mathrm{~mm}$ with 
a crosshead speed of $2 \mathrm{~mm} / \mathrm{min}$. The test samples had the dimensions of the $80 \times 25 \times 2 \mathrm{~mm}$, and the values given are the average of 6-9 specimens tested for each sample. Tensile analysis was carried out according to DIN EN ISO 527 [44] using a Zwick Roell universal testing machine at ambient temperature. The test samples had the dimensions $250 \times 25 \times 2 \mathrm{~mm}$. The testing speed was $2 \mathrm{~mm} / \mathrm{min}$ and the clamping length was $150 \mathrm{~mm}$ at start position. The reported values are an average of $5-7$ specimens tested. Charpy impact strength was done on the samples with the dimensions $80 \times 15 \times 2 \mathrm{~mm}$ according to the ISO 179 [45] standard at ambient temperature using a universal pendulum impact system by Ray-Ran (Nuneaton, UK). The specimens were tested on flatwise orientation. The hammer weight was $0.951 \mathrm{~kg}$ with a velocity of $2.9 \mathrm{~m} / \mathrm{s}$ and an impact energy of $3.99 \mathrm{~J}$. The reported values are for 6-9 specimens tested.

Heat deflection temperature was measured according to Vicat A (ISO 306) [46]. Start temperature was $40{ }^{\circ} \mathrm{C}$ and the heating rate was $50 \mathrm{~K} / \mathrm{h}$. For each specimen, three samples were tested.

The thermal conductivity of the composites was measured at $60{ }^{\circ} \mathrm{C}$. Each sample was tested four times.

\section{Results and Discussion}

\subsection{Influence of Fiber Hybridization at the Mechanical Performance of PP-Composites}

This section discusses the details of the hybridization of bast fibers with basalt and glass fibers, and an influence of the basalt fibers sizing at the overall composite performance. The density of the composites showed significant variations throughout the samples, which is a well-known phenomenon in the fiber-reinforced composites. Therefore, for a realistic comparison, the mechanical properties of the composites have been discussed and compared in terms of their specific mechanical properties. The density of the test specimens was estimated from their mass per volume, whereas the volume was calculated by their width, length, and thickness.

The mechanical analysis of the composites in transverse to the production direction gave the lowest mechanical properties and no influence of reinforcements, hybridization of fibers, or sizing could be observed. Therefore, the properties were investigated only in the production direction where the fibers are predominantly oriented.

\subsubsection{Flexural Analysis}

Table 3 presents the results of the flexural analysis in terms of specific flexural properties and the density of composites along with their standard deviation (sd).

Table 3. Flexural analysis and density of the composites.

\begin{tabular}{|c|c|c|c|c|c|c|}
\hline Sample & $\begin{array}{c}\text { Specific Flexural } \\
\left.\text { Modulus (MPa } \mathrm{cm}^{3} / \mathrm{g}\right)\end{array}$ & sd & $\begin{array}{c}\text { Specific Flexural } \\
\text { Strength }\left(\mathrm{MPa} \cdot \mathrm{cm}^{3} / \mathrm{g}\right)\end{array}$ & sd & $\begin{array}{l}\text { Density } \\
\left(\mathrm{g} / \mathrm{cm}^{3}\right)\end{array}$ & sd \\
\hline PP/KEFL & 2373 & 265 & 59 & 5 & 0.90 & 0.05 \\
\hline PP/5BA/KEFL & 2498 & 247 & 71 & 5 & 0.93 & 0.08 \\
\hline PP/10BA/KEFL & 3366 & 169 & 83 & 9 & 0.93 & 0.08 \\
\hline $\mathrm{PP} / 15 \mathrm{BA} / \mathrm{KEFL}$ & 3373 & 305 & 90 & 5 & 1.00 & 0.02 \\
\hline PP/25BA/KEFL & 3845 & 321 & 104 & 5 & 0.87 & 0.16 \\
\hline PP/25DBA/KEFL & 2863 & 319 & 72 & 10 & 0.88 & 0.07 \\
\hline PP/40BA/KEFL & 4610 & 564 & 109 & 6 & 0.70 & 0.07 \\
\hline PP/5GF/KEFL & 2141 & 150 & 59 & 5 & 0.89 & 0.07 \\
\hline PP/15GF/KEFL & 2704 & 273 & 62 & 5 & 0.74 & 0.03 \\
\hline PP/25GF/KEFL & 2901 & 213 & 77 & 5 & 1.04 & 0.06 \\
\hline
\end{tabular}

The flexural properties of the reference composite (PP/KEFL) and the hybridized composites with $5,10,15,25$, and $40 \mathrm{wt}$.\% of basalt fibers are shown in Figure 3. The graphic shows a gradual increase in modulus and strength by the increasing BA content. 

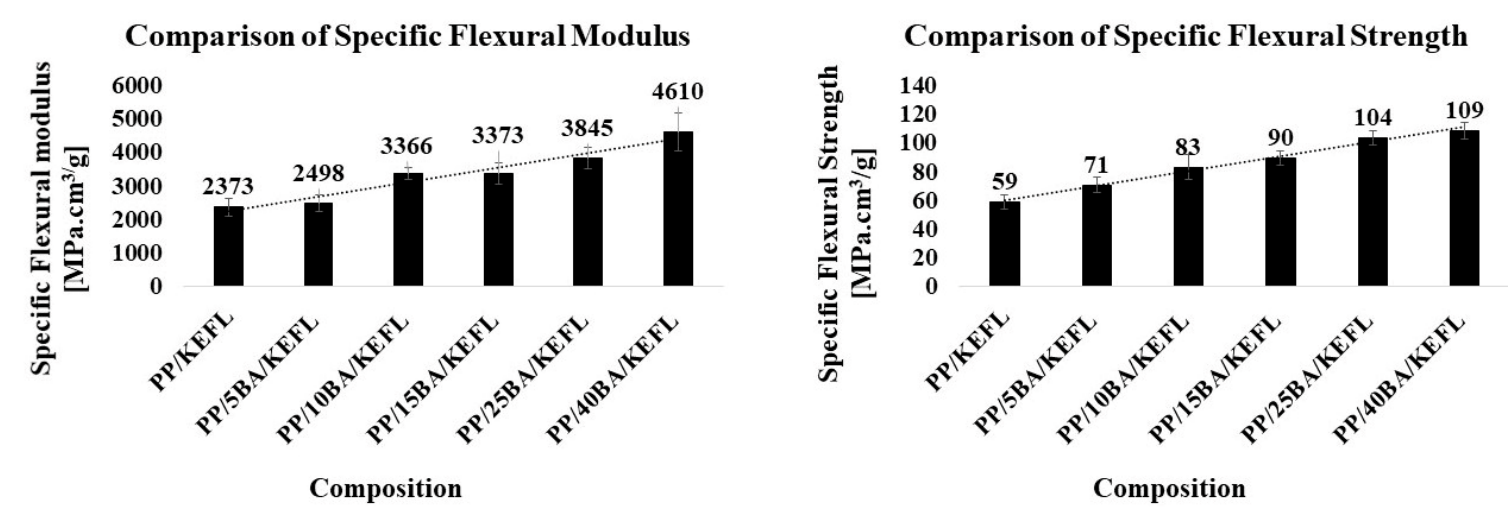

Figure 3. Flexural analysis of composites with bast and hybrid bast/BA fibers.

The composites with 25 wt.\% loading of BA (PP-size), DBA (Epoxy-size), and GF (PP-size) have been compared in Figure 4. BA composite shows a better performance compared to the others. In comparison with the reference composition, the composite with $25 \mathrm{wt} . \%$ of BA loading shows an increase of $62 \%$ in modulus and $76 \%$ in the strength. Whereas a similar comparison of DBF composite shows only a $21 \%$ increase in modulus and a $22 \%$ increase in strength. The sizing of BA fibers favors effective bonding with the matrix. In contrast, the sizing of DBF fibers is suitable for thermosets and therefore does not support an effective bonding with PP. This confirms that an appropriate sizing is an important deciding factor to achieve the optimal composite performance. It is important to mention that the mechanical performance of the fiber-reinforced composites does not depend only at the properties of constituents; they also depend upon the fiber-matrix interface, the region where actual stress transfer occurs from matrix to fibers. Future work on these composites would include a detailed analysis of fiber-matrix interaction for a thorough understanding of the mechanical performance of hybrid bast/basalt composites.
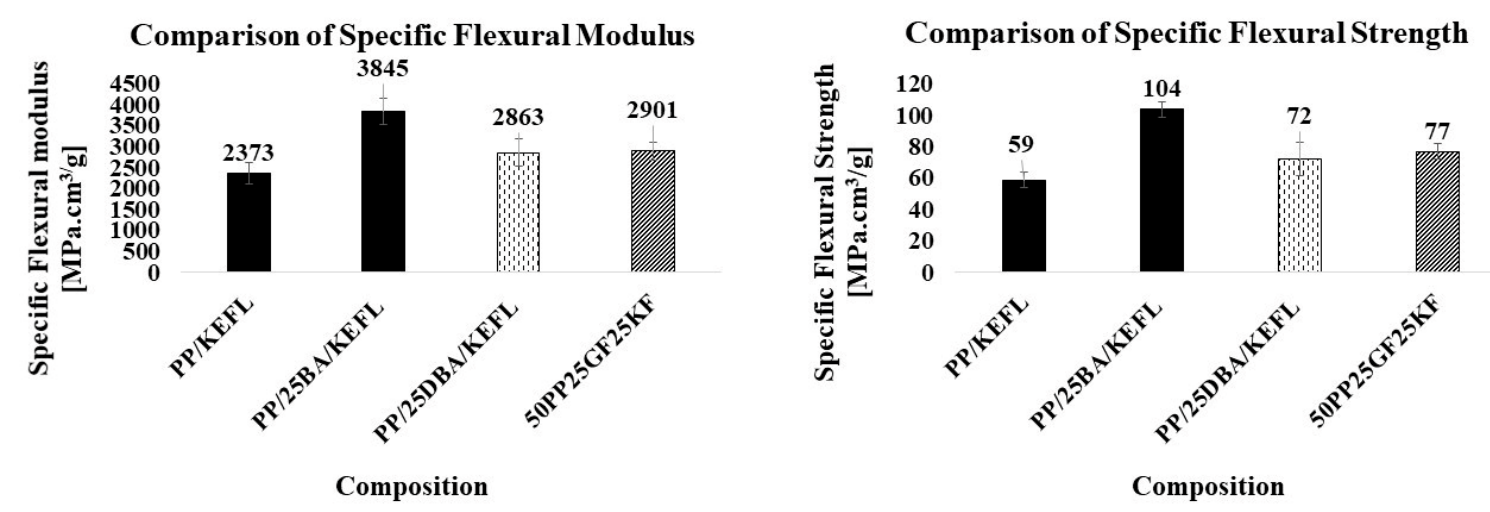

Figure 4. Flexural analysis of bast/basalt and bast/GF hybrid composite and a comparison with reference composite PP/KEFL.

A comparison with GF composite shows that even though BA and GF have the PP-sizing, the flexural modulus and strength of BA composite are higher than the GF composite. This can be explained because of the low mechanical properties of the GF that have already been established in Table 1.

\subsubsection{Tensile Analysis}

The tensile analysis and the density of the composites are summarized in Table 4. 
Table 4. Tensile analysis and density of the composites.

\begin{tabular}{ccccccc}
\hline Sample & $\begin{array}{c}\text { Specific Tensile } \\
\text { Modulus }\left(\mathbf{M P a} \cdot \mathbf{c m}^{\mathbf{3}} \mathbf{g}\right)\end{array}$ & sd & $\begin{array}{c}\text { Specific Tensile } \\
\text { Strength }\left(\mathbf{M P a} \cdot \mathbf{c m}^{\mathbf{3}} / \mathbf{g}\right)\end{array}$ & sd & $\begin{array}{c}\text { Density } \\
\left(\mathbf{g} / \mathbf{c m}^{3}\right)\end{array}$ & sd \\
\hline PP/KEFL & 5289 & 502 & 53 & 4 & 0.86 & 0.04 \\
PP/5BA/KEFL & 6151 & 828 & 65 & 6 & 0.91 & 0.08 \\
PP/10BA/KEFL & 6610 & 1616 & 73 & 3 & 0.93 & 0.06 \\
PP/25BA/KEFL & 7078 & 273 & 86 & 8 & 0.90 & 0.16 \\
PP/25DBA/KEFL & 7010 & 557 & 62 & 0 & 0.96 & 0.08 \\
PP/40BA/KEFL & 7311 & 314 & 94 & 5 & 0.73 & 0.04 \\
PP/5GF/KEFL & 5294 & 527 & 58 & 3 & 0.96 & 0.06 \\
PP/15GF/KEFL & 5706 & 941 & 62 & 4 & 0.96 & 0.07 \\
PP/25GF/KEFL & 6312 & 1163 & 65 & 2 & 1.04 & 0.11 \\
\hline
\end{tabular}

Figure 5 shows a trend that the tensile modulus and strength increase by the increasing amount of basalt. On an average, there is a $28 \%$ increase in modulus and about $50 \%$ increase in tensile strength up to $40 \mathrm{wt}$ \% loading of BA.
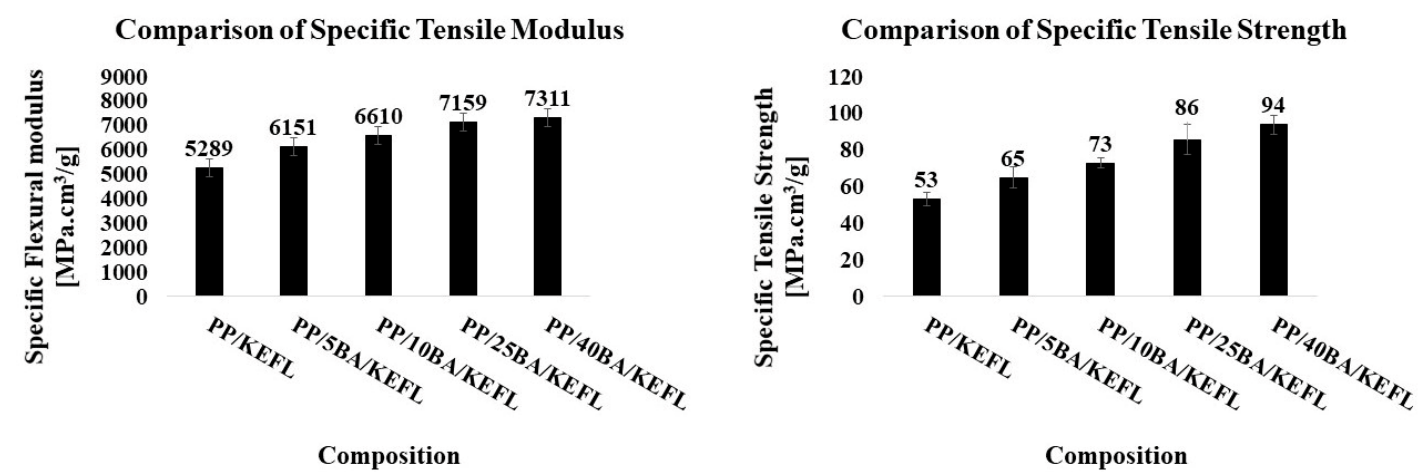

Figure 5. Tensile analysis of PP composites with bast and hybrid bast/BA fibers.

Compared to the reference composite (Figure 6), there is 35\% increase in modulus and $62 \%$ increase in strength at $25 \mathrm{wt}$.\% loading of BA fibers. Whereas in the case of hybrid bast/DBA composite at $25 \mathrm{wt} . \%$ loading of DBA, there is $32 \%$ increase in modulus and only $17 \%$ increase in the strength compared to the reference composite. The tensile modulus seems to be unaffected by the basalt fiber sizing compared to the tensile strength. This is unlike flexural properties where both modulus and strength are significantly affected by the fiber sizing. This could be because the sample is under tensile and compressive forces during the flexural analysis provides an evident change of flexural behaviour at various fiber sizings that influence the fiber-matrix interaction [30].
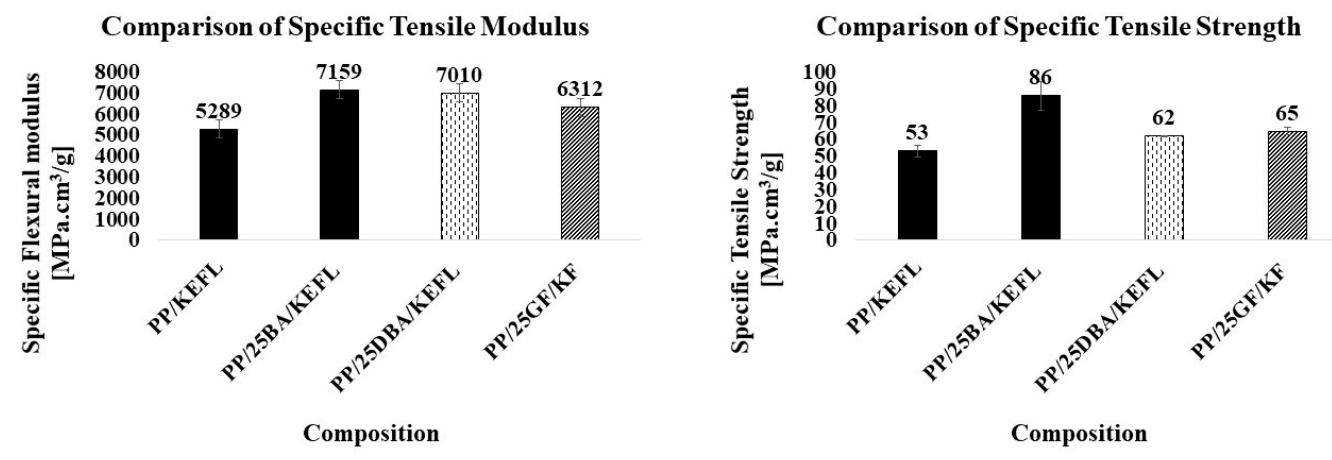

Figure 6. Tensile analysis of bast/basalt and bast/GF hybrid composite and a comparison with reference composite PP/KEFL. 
Figure 6 compares the performance of hybrid bast/BA composite with the hybrid bast/GF composite as well. The tensile modulus of $25 \mathrm{wt} . \%$ BA composite is $13 \%$ and strength is $32 \%$ higher than the GF composite.

The tensile analysis clearly shows that the basalt fibers with PP sizing play a role in improving the tensile properties. Moreover, the properties of basalt composites are higher than the GF composites, which is the result of better tensile properties of the basalt fibers than the GF (Table 1).

\subsubsection{Impact Energy Absorption}

The impact energy absorption analysis of the PP composites is given in Table 5.

Table 5. Impact energy absorption analysis (Charpy) and density of the composites.

\begin{tabular}{|c|c|c|c|c|}
\hline Sample & $\begin{array}{l}\text { Specific Impact Energy } \\
\left(\mathrm{kJ} / \mathrm{m}^{2} \cdot \mathrm{cm}^{3} / \mathrm{g}\right)\end{array}$ & sd & Density $\left(\mathrm{g} / \mathrm{cm}^{3}\right)$ & sd \\
\hline PP/KEFL & 29 & 3 & 0.86 & 0.07 \\
\hline PP/5BA/KEFL & 33 & 1 & 0.95 & 0.09 \\
\hline PP/10BA/KEFL & 34 & 3 & 0.89 & 0.06 \\
\hline $\mathrm{PP} / 15 \mathrm{BA} / \mathrm{KEFL}$ & 35 & 3 & 0.82 & 0.04 \\
\hline PP/25BA/KEFL & 40 & 2 & 0.83 & 0.10 \\
\hline PP/25DBA/KEFL & 46 & 6 & 0.73 & 0.13 \\
\hline PP/40BA/KEFL & 42 & 2 & 0.82 & 0.03 \\
\hline $\mathrm{PP} / 5 \mathrm{GF} / \mathrm{KEFL}$ & 38 & 3 & 0.92 & 0.38 \\
\hline PP/15GF/KEFL & 39 & 4 & 0.65 & 0.06 \\
\hline PP/25GF/KEFL & 42 & 2 & 0.87 & 0.07 \\
\hline
\end{tabular}

Figure 7 shows that the energy absorption increases by the increasing amount of BA. This depicts that the basalt fibers do not just improve the tensile and flexural properties, they also improve the impact strength of the composites, which is a key requirement in the automobile industry.

\section{Comaprison of Specific Impact Strength}

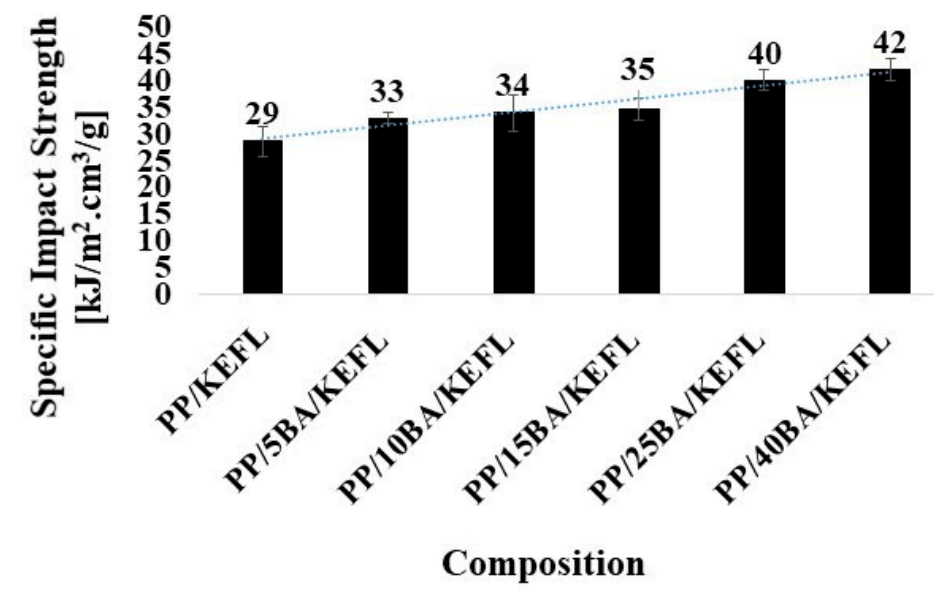

Figure 7. Specific impact strength of PP composites with bast and hybrid bast/BA fibers.

A comparison of the composites with $25 \mathrm{wt}$.\% loading of BA, DBA, and GF is presented in Figure 8. It can be seen that energy absorption is the highest for the composite with $25 \mathrm{wt}$. $\%$ loading of DBF fibers. This is an expected finding and could be explained by the previous literature $[30,47]$ that shows that the composites with effective fiber-matrix interaction absorb less impact energy compared to the composites with poor interaction. Poor adhesion leads to a greater number of pullout fibers, which could create a fiber bridge leading to an increase in energy absorption. Therefore, the findings of impact energy analysis are quite convincing and relevant to the previous tensile and flexural analysis. 


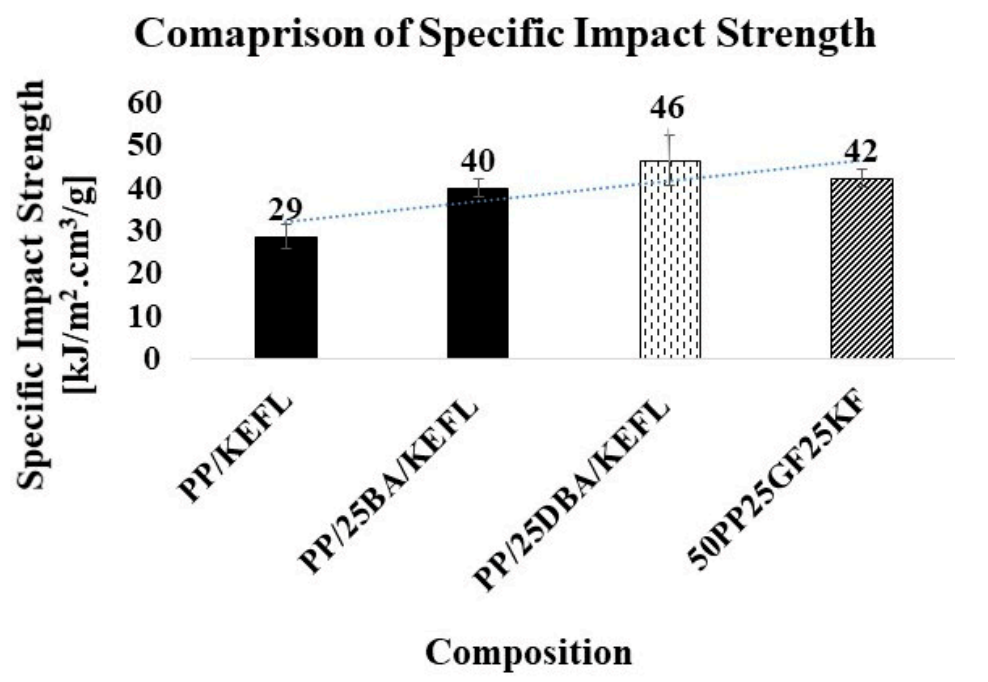

Figure 8. Comparison of impact energy absorption with bast/GF hybrid composite.

\subsubsection{SEM Analysis}

SEM analysis of the fractured surface of tensile samples was carried out to get an insight into the morphology of the composites. The analysis shows a homogeneous distribution of various fibers in the composites without any agglomeration or overlapping of various kinds of fibers. The enlarged view of PP/25DBA/KEFL composite in Figure 9 shows several pullout fibers. A closer view shows the sleek and clear basalt fiber surface without any perceptible matrix residue, an indication of the poor fiber-matrix boundary. This is the weak interfacial region where failure occurs under stress [48].
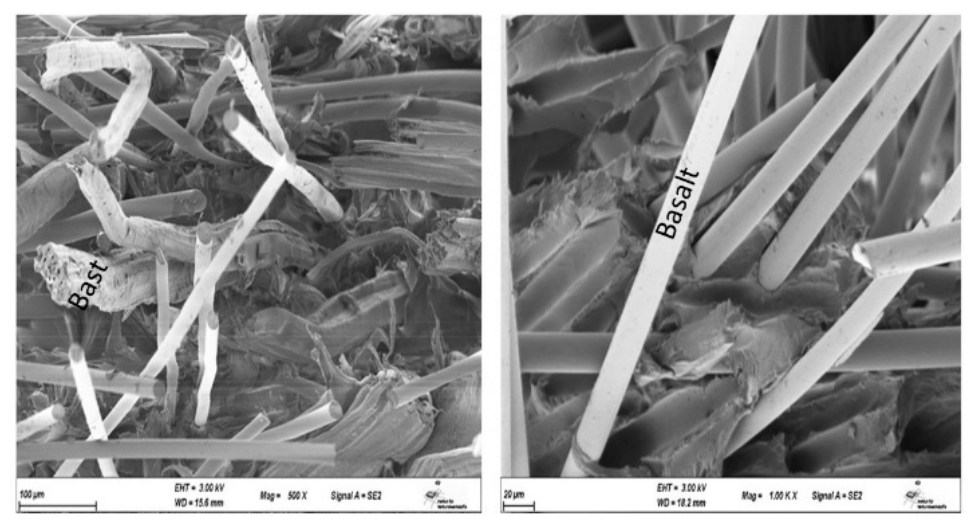

Figure 9. SEM Analysis: Wide and close view of tensile fracture surface of PP/25DBA/KEFL composite.

The morphology of PP/25BA/KEFL composite in Figure 10 shows fewer pullout fibers compared to the PP/25DBA/KEFL composite. Basalt fibers seem to be better embedded in the matrix, which is stranded among the fibers indicating an effective adhesion with the fibers. The area marked in the Figure 10 shows distinct matrix residue at the basalt surface. The SEM analysis has confirmed the results of mechanical analysis. It verifies the assumption that the appropriate sizing of BA improves the fiber-matrix bonding. Figure 11 illustrates the SEM analysis of PP/25GF/KEFL composite. A close view shows the matrix residue at the GF, an indication of good fiber-matrix interaction. However, the matrix is not stranded among the fibers like the $25 \mathrm{wt} . \%$ BA composite. 

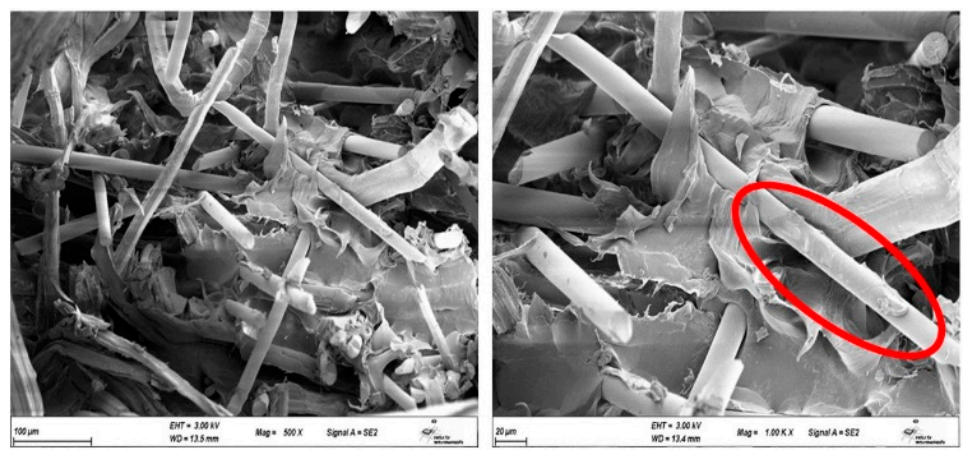

Figure 10. SEM analysis of tensile fracture surface of PP/25BA/KEFL composite showing matrix residue (marked) on BA fibers and stranded matrix between the fibers.

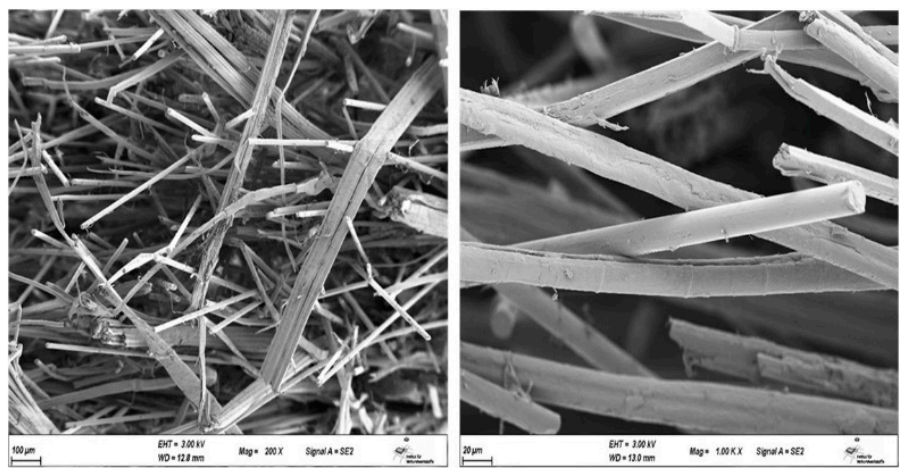

Figure 11. SEM analysis of PP/25GF/KEFL composite.

\subsubsection{Thermal Analysis}

Table 6 shows the heat deflection temperature (HDT) and the thermal conductivity of the PP hybrid composites. At $25 \mathrm{wt} . \%$ loading of BA and DBA fibers in PP there is about a $70 \%$ increase in HDT. The increase in HDT demonstrates that the addition of basalt fibers decisively improves the thermal stability of the composites. The influence of basalt fibers coating is not pronounced at the HDT. The BA and DBA fibers have affected the temperature in an almost similar manner.

Table 6. HDT and thermal conductivity of PP composites.

\begin{tabular}{ccccc}
\hline Sample & HDT $\left({ }^{\circ} \mathbf{C}\right)$ & sd & $\begin{array}{c}\text { Thermal Conductivity } \\
(\mathbf{W} / \mathbf{M k})\end{array}$ & sd \\
\hline PP/KEFL & 52 & 3 & 0.172 & 0.001 \\
PP/25BA/KEFL & 89 & 1 & 0.265 & 0.003 \\
PP/25DBA/KEFL & 88 & 7 & 0.268 & 0.002 \\
\hline
\end{tabular}

The thermal conductivity of PP samples increased on an average by $55 \%$ by the addition of $25 \mathrm{wt} . \%$ basalt. Here also, just like for HDT, the influence of fiber coating cannot be distinguished. Both BA and DBA fibers are influencing the thermal conductivity in the same way. In summary, it can be accredited that the composites hybridized with basalt show an overall improved thermal performance compared to the reference samples.

\subsection{Influence of Modified PP (PP-g-MA) at the Mechanical Performance of Hybrid Composites}

An additive that has been extensively studied for improving the bonding between natural fibers and PP is maleic anhydride that has certainly shown improvements in adhesion of polymer with natural fibers $[49,50]$. The PP portion of PP-g-MA entangles and co-crystallizes with unmodified 
$\mathrm{PP}$, whereas the maleic anhydride groups can chemically bond to the hydroxyl groups on fibers [32]. The flexural and impact energy analysis of the PP and PP-g-MA composites is given in Table 7.

Table 7. Flexural and impact energy absorption analysis of PP and PP-g-MA composites.

\begin{tabular}{|c|c|c|c|c|c|c|c|c|c|c|}
\hline \multirow[b]{2}{*}{ Sample } & \multicolumn{6}{|c|}{ Flexural Analysis } & \multicolumn{4}{|c|}{ Impact Strength } \\
\hline & $\begin{array}{l}\text { Specific } \\
\text { Flexural } \\
\text { Modulus } \\
\left(\mathrm{MPa} \cdot \mathrm{cm}^{3} / \mathrm{g}\right)\end{array}$ & sd & $\begin{array}{l}\text { Specific } \\
\text { Flexural } \\
\text { Strength } \\
\left(\mathrm{MPa} \cdot \mathrm{cm}^{3} / \mathrm{g}\right)\end{array}$ & sd & $\begin{array}{l}\text { Density } \\
\left(\mathrm{g} / \mathrm{cm}^{3}\right)\end{array}$ & sd & $\begin{array}{c}\text { Specific } \\
\text { Impact } \\
\text { Strength } \\
\left(\mathrm{kJ} / \mathrm{m}^{2} \cdot \mathrm{cm}^{3} / \mathrm{g}\right)\end{array}$ & sd & $\begin{array}{l}\text { Density } \\
\left(\mathrm{g} / \mathrm{cm}^{3}\right)\end{array}$ & sd \\
\hline $\mathrm{PP} / \mathrm{KEFL}$ & 2373 & 265 & 59 & 5 & 0.90 & 0.05 & 29 & 3 & 0.86 & 0.07 \\
\hline PP-g-MA/KEFL & 3616 & 312 & 71 & 6 & 0.95 & 0.14 & 19 & 2 & 0.90 & 0.16 \\
\hline PP/25BA/KEFL & 3845 & 321 & 104 & 5 & 0.87 & 0.16 & 40 & 2 & 0.83 & 0.10 \\
\hline PP-g-MA/25BA/KEFL & 4342 & 145 & 110 & 4 & 0.92 & 0.09 & 33 & 2 & 1.5 & 0.04 \\
\hline
\end{tabular}

A comparison of the flexural properties of the PP and modified PP composites is presented in Figure 12. Compared to the PP/KEFL, the reference composite, the flexural modulus increased by $52 \%$ and the strength by $20 \%$ for PP-g-MA/KEFL composite. This shows that the bast fibers have a better bonding with the modified PP compared to the unmodified PP. The flexural modulus and strength of PP-g-MA/25BA/KEFL increased by $83 \%$ and $86 \%$, respectively, compared to the PP/KEFL composite. In contrast, the modulus and strength of hybrid PP composite increase by $62 \%$ and $76 \%$, respectively, compared to the reference composite. The flexural properties of the modified PP composites are significantly higher compared to the respective PP composites and the reference composition. The modified PP does not just support a better bonding with BA fibers, but also with bast fibers.
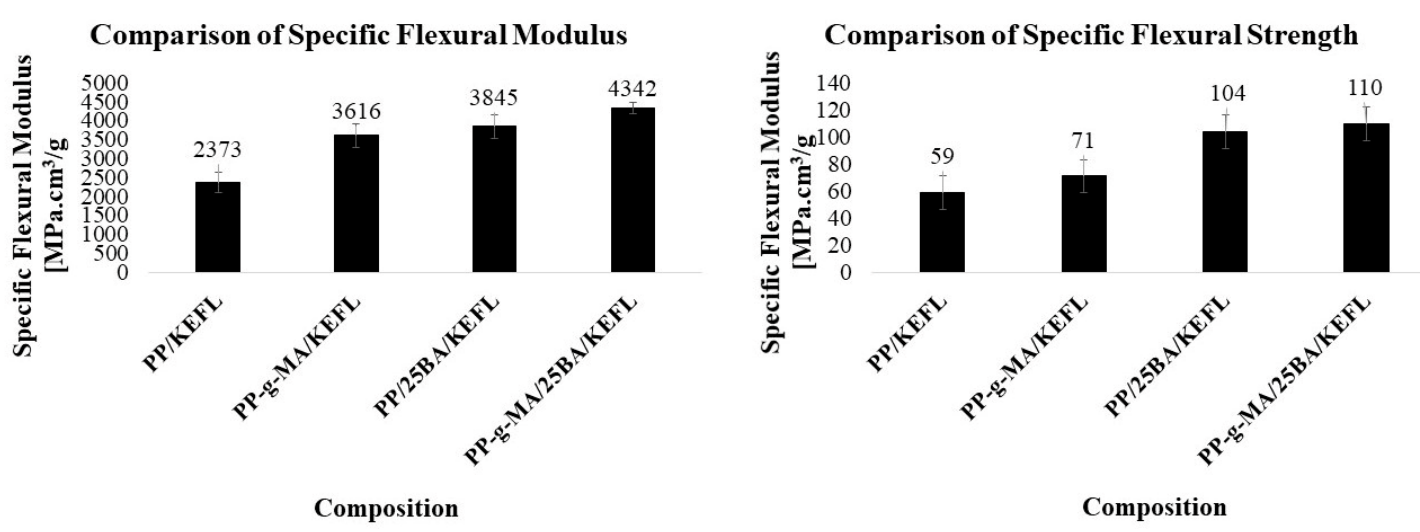

Figure 12. Comparison of the flexural properties of PP composites with modified PP composites.

As expected, the impact energy absorption is low for the modified PP composites compared to the respective PP composites (Figure 13). The reason for this is obviously the better fiber-matrix interaction in the case of modified PP composites. As explained above, a composite with better fiber-matrix bonding shows fewer pullout fibers in the impact energy analysis and absorbs less energy compared to a composite with poor fiber-matrix interaction. 


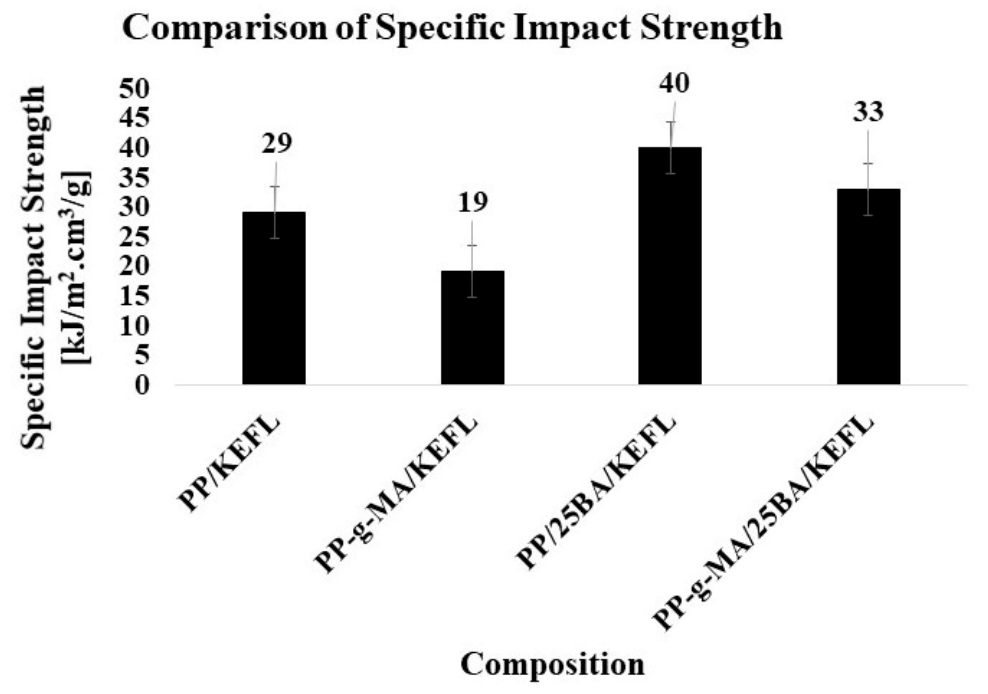

Figure 13. Comparsion of impact strength of PP composites with modified PP composites.

\section{Conclusions}

Within this research work, natural fiber reinforced PP composites were successfully prepared by carding and compression molding. The bast fiber (flax + kenaf) content of the composites was partially replaced by high-performance basalt fibers. The compression-molded samples were used to get the test specimens for mechanical and thermal analyses. The mechanical characterization of the composites includes the analysis of their tensile, flexural, and impact energy absorption properties. Since the material- and process-related density variations in the samples influence the composite properties, the specific mechanical properties of the composites were considered for a better comparison.

The properties of the composites hybridized with basalt fibers showed a significant increase in the overall part performance. The basalt fibers with a sizing suitable for PP (BA) better enhanced mechanical properties than the basalt fibers with a sizing for thermosets (DBA). However, they both influenced the thermal properties in a similar manner. Moreover, it was confirmed that the mechanical performance of the composites could be improved further when the BA fibers were hybridized in modified PP (PP-g-MA). However, coating the fibers is a much more convenient and economical process than the polymer modification.

Since there is a lack of reference literature for the basalt fibers in hybrid polymer composites, the novel compositions developed in this project were compared with a hybridization of bast and glass fibers in PP matrix, manufactured under the same conditions, like the bast/basalt-based composites. The tensile analysis of the single fibers showed that the basalt fibers have comparatively higher properties than the glass fibers. A comparison of the mechanical properties of the composites also showed that the bast/basalt hybrid composites have a higher mechanical profile compared to the bast/GF hybrid composites. The results support the idea of replacing glass fibers in certain applications with basalt fibers since they have the advantage of being environmentally friendly and non-toxic.

Scanning electron micrographs (SEM) of the composites were recorded for their morphological analysis. SEM analysis supported the mechanical characterization of the composites. The composites with BA fibers showed a much more effective fiber-matrix interaction compared to the composites with DBA fibers. Furthermore, the analysis showed a homogeneous distribution of the various fibers in the composites without any agglomeration or overlapping.

The thermal characterization of the samples was done by analyzing their heat deflection temperature and thermal conductivity. Basalt fibers have potential to improve the composites performance not just mechanically, but also thermally. In contrast to the mechanical properties, the thermal properties were unaffected by the fiber sizing. Both BA and DBA fibers significantly improved the thermal properties and in the same manner. 
The developed bast/basalt hybrid composites manifest excellent properties and potential to replace the synthetic fibers in structural applications. Their possible use could be in the load-bearing, shock absorption, and thermal management areas. Though the developed composites are attractive and offer many benefits compared to the glass fibers, there is still a dearth of research about the mechanical, thermal, and chemical resistance properties of the basalt fibers in hybrid polymer composites. More contributions are required, and important technical considerations must be addressed before they are widely accepted in the scientific and commercial community.

Author Contributions: For the research article the individual contributions are provided below: conceptualization, methodology, project administration: L.M. and A.S.; formal analysis, investigation, resources, data curation, writing-original draft preparation: A.S.; review and editing: L.M. and M.S.; supervision, L.M. and M.S. All authors have read and agreed to the published version of the manuscript.

Funding: This research received no external funding.

Acknowledgments: Authors would like to thank the company J. Dittrich \& Söhne Vliesstoffwerk GmbH for supplying the bast fibers, to the company Fibtex $\mathrm{GmbH}$ and Beaulieu International Group, Belgium for providing basalt and polypropylene fibers, respectively. Special thanks to Schuster, at University of Applied Sciences, Kaiserslautern for providing his lab facilities for mechanical analysis. Thanks to the Institute für Verbundwerkstoffe $\mathrm{GmbH}$ in Kaiserslautern for providing the SEM pictures of the composites.

Conflicts of Interest: The authors declare no conflict of interest.

\section{References}

1. Directive 2000/53/EC of the European Parliament and of the Council of 18 September 2000 on End of life vehicles. Off. J. Eur. Union L Ser. 2000, 269, 34-42.

2. Mohanty, A.K.; Misra, M.; Drzal, L.T. Natural Fibers, Biopolymers, and Biocomposites: An Introduction. In Natural Fibers, Biopolymers, and Biocomposites; Taylor \& Francis: Boca Raton, FL, USA, 2005; pp. 2-31, ISBN 978-0-8493-1741-5.

3. Mueller, D.H.; Krobjilowski, A. New discovery in the properties of composites reinforced with natural fibers. J. Ind. Text. 2003, 33, 111-130. [CrossRef]

4. Ferreira, F.; Pinheiro, I.; de Souza, S.; Mei, L.; Lona, L. Polymer composites reinforced with natural fibers and nanocellulose in the automotive industry: A short review. J. Compos. Sci. 2019, 3, 51. [CrossRef]

5. Beardmore, P.; Johnson, C.F. The potential for composites in structural automotive applications. Compos. Sci. Technol. 1986, 26, 251-281. [CrossRef]

6. Yates, M.R.; Barlow, C.Y. Life cycle assessments of biodegradable, commercial biopolymers-A critical review. Resour. Conserv. Recycl. 2013, 78, 54-66. [CrossRef]

7. Witten, E.; Kraus, T.; Kühnel, M. Composites Market Report 2014: Market Developments, Trends, Challenges and Opportunities; Carbon Composites: Augsburg, Germany, 2014.

8. Holbery, J.; Houston, D. Natural-fiber-reinforced polymer composites in automotive applications. JOM 2006, 58, 80-86. [CrossRef]

9. Rajak, D.; Pagar, D.; Menezes, P.; Linul, E. Fiber-reinforced polymer composites: Manufacturing, properties, and applications. Polymers 2019, 11, 1667. [CrossRef]

10. Summerscales, J.; Dissanayake, N.P.J.; Virk, A.S.; Hall, W. A review of bast fibres and their composites. Part 1-Fibres as reinforcements. Compos. Part A Appl. Sci. Manuf. 2010, 41, 1329-1335. [CrossRef]

11. Carus, M.; de Beus, N.; Barth, M. Carbon Footprint and Sustainability of Different Natural Fibres for Biocomposites and Insulation Material; Nova-Institute: Hürth, Germany, 2019.

12. Medina, L.A.; Dzalto, J. 1.11 Natural Fibers. In Comprehensive Composite Materials II; Elsevier: Amsterdam, The Netherlands, 2018; pp. 269-294, ISBN 978-0-08-100534-7.

13. Sojoudiasli, H.; Heuzey, M.-C.; Carreau, P.J. Rheological, morphological and mechanical properties of flax fiber polypropylene composites: Influence of compatibilizers. Cellulose 2014, 21, 3797-3812. [CrossRef]

14. Notta-Cuvier, D.; Lauro, F.; Bennani, B.; Nciri, M. Impact of natural variability of flax fibres properties on mechanical behaviour of short-flax-fibre-reinforced polypropylene. J. Mater. Sci. 2016, 51, 2911-2925. [CrossRef] 
15. Müssig, J.; Graupner, N. Technical applications of natural fibers: An Overview. In Industrial Application of Natural Fibres: Structure, Properties, and Technical Applications; Wiley series in renewable resources; Wiley: Chichester, UK; Hoboken, NJ, USA, 2010; pp. 63-88, ISBN 978-0-470-69508-1.

16. Santulli, C. Impact properties of glass/plant fibre hybrid laminates. J. Mater. Sci. 2007, 42, 3699-3707. [CrossRef]

17. Sathishkumar, T.; Naveen, J.; Satheeshkumar, S. Hybrid fiber reinforced polymer composites-A review. J. Reinf. Plast. Compos. 2014, 33, 454-471. [CrossRef]

18. Petrucci, R.; Santulli, C.; Puglia, D.; Nisini, E.; Sarasini, F.; Tirillò, J.; Torre, L.; Minak, G.; Kenny, J.M. Impact and post-impact damage characterisation of hybrid composite laminates based on basalt fibres in combination with flax, hemp and glass fibres manufactured by vacuum infusion. Compos. Part B Eng. 2015, 69, 507-515. [CrossRef]

19. Cheng, M.; Zhong, Y.; Kureemun, U.; Cao, D.; Hu, H.; Lee, H.P.; Li, S. Environmental durability of carbon/flax fiber hybrid composites. Compos. Struct. 2020, 234, 111719. [CrossRef]

20. Ray, K.; Patra, H.; Swain, A.K.; Parida, B.; Mahapatra, S.; Sahu, A.; Rana, S. Glass/jute/sisal fiber reinforced hybrid polypropylene polymer composites: Fabrication and analysis of mechanical and water absorption properties. Mater. Today Proc. 2020. [CrossRef]

21. Rakesh, P.; Diwakar, V.; Venkatesh, K.; Savannananavar, R.N. A concise report on properties of hybrid composites manufactured from glass and natural fibers. Mater. Today Proc. 2020, 22, 2008-2015. [CrossRef]

22. Lopresto, V.; Leone, C.; De Iorio, I. Mechanical characterization of basalt fibre reinforced plastic. Compos. Part B Eng. 2011, 42, 717-723. [CrossRef]

23. Fiore, V.; Scalici, T.; Di Bella, G.; Valenza, A. A review on basalt fibre and its composites. Compos. Part B Eng. 2015, 74, 74-94. [CrossRef]

24. Singha, K. A short review on basalt fiber. Int. J. Text. Sci. 2012, 1, 19-28. [CrossRef]

25. Deák, T.; Czigány, T. Chemical composition and mechanical properties of basalt and glass Fibers: A comparison. Text. Res. J. 2009, 79, 645-651. [CrossRef]

26. Manikandan, V.; Winowlin Jappes, J.T.; Suresh Kumar, S.M.; Amuthakkannan, P. Investigation of the effect of surface modifications on the mechanical properties of basalt fibre reinforced polymer composites. Compos. Part B Eng. 2012, 43, 812-818. [CrossRef]

27. Saleem, A.; Medina, L.; Skrifvars, M. Mechanical performance of hybrid bast and basalt fibers reinforced polymer composites. J. Polym. Res. 2020, 27, 61. [CrossRef]

28. Wei, B.; Song, S.; Cao, H. Strengthening of basalt fibers with nano-SiO2-epoxy composite coating. Mater. Des. 2011, 32, 4180-4186. [CrossRef]

29. Bashtannik, P.I.; Kabak, A.I.; Yakovchuk, Y.Y. The effect of adhesion interaction on the mechanical properties of thermoplastic basalt plastics. Mech. Compos. Mater. 2003, 39, 85-88. [CrossRef]

30. Ralph, C.; Lemoine, P.; Archer, E.; McIlhagger, A. Mechanical properties of short basalt fibre reinforced polypropylene and the effect of fibre sizing on adhesion. Compos. Part B Eng. 2019, 176, 107260. [CrossRef]

31. Joseph, P.V.; Rabello, M.S.; Mattoso, L.H.C.; Joseph, K.; Thomas, S. Environmental effects on the degradation behaviour of sisal fibre reinforced polypropylene composites. Compos. Sci. Technol. 2002, 62, 1357-1372. [CrossRef]

32. Bullions, T.A.; Gillespie, R.A.; Price-O'Brien, J.; Loos, A.C. The effect of maleic anhydride modified polypropylene on the mechanical properties of feather fiber, kraft pulp, polypropylene composites. J. Appl. Polym. Sci. 2004, 92, 3771-3783. [CrossRef]

33. Karmaker, A.C.; Youncquist, J.A. Injection molding of polypropylene reinforced with short jute fibers. J. Appl. Polym. Sci. 1996, 62, 1147-1151. [CrossRef]

34. Salleh, F.M.; Hassan, A.; Yahya, R.; Lafia-Araga, R.A.; Azzahari, A.D.; Nazir, M.N.Z.M. Improvement in the mechanical performance and interfacial behavior of kenaf fiber reinforced high density polyethylene composites by the addition of maleic anhydride grafted high density polyethylene. J. Polym. Res. 2014, 21, 439. [CrossRef]

35. Greco, A.; Maffezzoli, A.; Casciaro, G.; Caretto, F. Mechanical properties of basalt fibers and their adhesion to polypropylene matrices. Compos. Part B Eng. 2014, 67, 233-238. [CrossRef]

36. Xu, H.; Zhou, H.; Chen, X.; Liu, Y. High thermal conductive composites based on flake graphite filled in a partial compatible polyamide 6/polypropylene. Polym. Sci. Ser. A 2015, 57, 644-655. [CrossRef] 
37. Guo, J.; Mu, S.; Yu, C.; Hu, C.; Guan, F.; Zhang, H.; Gong, Y. Mechanical and thermal properties of polypropylene/modified basalt fabric composites. J. Appl. Polym. Sci. 2015, 132. [CrossRef]

38. Lu, Z.; Xian, G.; Rashid, K. Creep Behavior of Resin Matrix and Basalt Fiber Reinforced Polymer (BFRP) Plate at Elevated Temperatures. J. Compos. Sci. 2017, 1, 3. [CrossRef]

39. Idumah, C.I.; Hassan, A. Effect of exfoliated graphite nanoplatelets on thermal and heat deflection properties of kenaf polypropylene hybrid nanocomposites. J. Polym. Eng. 2016, 36, 877-889. [CrossRef]

40. Textiles-Determination of Linear Density_Gravimetric Method and Vibroscope Method (ISO 1973:1995); Beuth Verlag GmbH: Berlin, Germany, 1995.

41. Textiles_Fibres_Determination of Breaking Force and Elongation at Break of Individual Fibres (ISO 5079:1979); Beuth Verlag GmbH: Berlin, Germany, 1995.

42. Boss, H.; Van de Oeven, M.; Molenveld, K. Influence of Fiber Structure on Composite Properties. In Proceedings of the 5th Global Wood and Natural Fibre Composites Symposium, Kassel, Germany, 27-28 April 2004.

43. Plastics-Determination of Flexural Properties (ISO 178:2019); Beuth Verlag GmbH: Berlin, Germany, 2019.

44. Plastics-Determination of Tensile Properties-Part 4: Test Conditions for Isotropic and Anisotropic Fibre-Reinforced Plastic Composites (ISO 527-4:1997); Beuth Verlag GmbH: Berlin, Germany, 1997.

45. Plastics-Determination of Charpy Impact Properties - Part 1: Non-Instrumented Impact Test (ISO 179-1:2010-06); Beuth Verlag GmbH: Berlin, Germany, 2010.

46. Plastics-Thermoplastic Materials_Determination of Vicat Softening Temperature (VST); Beuth Verlag GmbH: Berlin, Germany, 2013.

47. Spearing, S.M.; Evans, A.G. The role of fiber bridging in the delamination resistance of fiber-reinforced composites. Acta Metall. Mater. 1992, 40, 2191-2199. [CrossRef]

48. Chou, C.T.; Gaur, U.; Miller, B. Fracture mechanisms during fiber pull-out for carbon-fiber-reinforced thermosetting composites. Compos. Sci. Technol. 1993, 48, 307-316. [CrossRef]

49. Karnani, R.; Krishnan, M.; Narayan, R. Biofiber-reinforced polypropylene composites. Polym. Eng. Sci. 1997, 37, 476-483. [CrossRef]

50. Ichazo, M.N.; Albano, C.; González, J.; Perera, R.; Candal, M.V. Polypropylene/wood flour composites: Treatments and properties. Compos. Struct. 2001, 54, 207-214. [CrossRef] 